\title{
An Adaptive Pipe Diameter Flexible Expansion Centering Device
}

\author{
Shanshan SONG ${ }^{1,2}$, Jianfeng LI ${ }^{1,2}$, Jie SUN ${ }^{1,2}$ \\ ${ }^{1}$ School of Mechanical Engineering, Shandong University, Jinan, Shandong 250061, China \\ ${ }^{2}$ Key Laboratory of High Efficiency and Clean Mechanical Manufacture of Ministry of Education, \\ Shandong University, Jinan, Shandong 250061, China
}

\section{Keywords: Expansion Centering; Adaptive Pipe Diameter; Finite Element Method}

\begin{abstract}
In order to meet the need of modern warfare, improve the accuracy and reliability of gun shooting, scholars have started research on the barrel bore parameter detection equipment. The centering device of detection equipment will directly affect the accuracy of it. A kind of adaptive diameter flexible expansion centering device was designed to ensure the centering accuracy of detection equipment. The process of expansion centering was simulated by using the ABAQUS finite element software non-linear analysis technology which can obtain the amount of taper-lock radial expansion under different expanding mandrel body axial displacement, find out the relationship between expanding mandrel body axial displacement with the amount of taper-lock radial expansion. That provides the basis for designing centering device. The stress concentration area of taper-lock during centering process was found out by analysis the stress value of flexible taper-lock under different expanding mandrel body axial displacement, which can put forward the optimization scheme. The phenomenon of stress concentration of taper-lock is reduced effectively through optimizing processing.
\end{abstract}

\section{Introduction}

Artillery is a common weapon of modern warfare. It plays an important role in the national defense modernization. Development of high precision barrel bore parameter online testing equipment has become research focus. Domestic and international scholars have started research on this issues which developed different parameters of the barrel bore testing equipment. In the early 1980s, United States and Germany have begun research on gun barrel quality photodetector device [1], using optical collimators and moving centering target to detect the straightness of barrel. In the domestic, previous research mostly adopted the gauge, lever and optical axis detection method [2-3], while recent researches mainly adopt photoelectric measuring method. By using this method, Changchun University of Technology and Zhejiang University [4-5] were designed barrel NDT systems which composed by the detector, bore crawling, lasers and collimator. The detection principle was the test equipment moved by driving devices in the barrel. It will start work when the designated measuring position was reached and stop when the whole barrel was detected. The key test is to ensure that the detection devices are located in the axis of the barrel. The role of centering device is to achieve supporting the measure0ment component and the inner wall of the gun barrel, ensure the detection device is located in the axis of the barrel.

Different principles centering device were developed by various institutions. Jilin and Changchun University [6-7] were both designed testing equipment by using the cooperating relationship between positional column and barrel trunking to achieve the centering function. Sichuan University [8] designed a swelling centering device which composed by a piston, the swelling body and the springs. Features of this device were cylindrical measuring body grooved and the swelling body embed into the trench. The upper end face of swelling body was cambered. North University [9] designed the centering device of testing equipment composed by three T-type pull rods which were equipped with moving wheel. Under the action of compression spring the balance system will return to balance when the detection aperture was changed. The roller will always fit with the tube wall to achieve 
the purpose of centering.

All above those devices to realize centering were both by way of point contact which contact area was small, centering accuracy was low. It's difficulty to meet the high precision centering demand of testing equipment. In this paper, based on the principle of expansion sets, the process of expansion centering was simulated by using the ABAQUS finite element software non-linear analysis technology which can obtain the amount of taper-lock radial expansion under different expanding mandrel body axial displacement, find out the relationship between expanding mandrel body axial displacement with the amount of taper-lock radial expansion. A kind of adaptive diameter flexible expansion centering device was designed. The centering contact area was surface which improved the reliability of centering device and ensured the accuracy of the detection device.

\section{The centering device structure and working principle}

A new type of adaptive diameter flexible expansion centering device was designed by applying expansion positioning principle, as shown in figure1. This device was consisted of taper-lock, expanding mandrel body, motor bracket, motor and drive screw, etc. By using two expansion sets to achieve the high precision and reliability centering requirement. The structure of flange was used in taper-lock, as shown in figure2. Contact area which between taper-lock and expanding mandrel body was conical. Two expanding mandrel will start axial movement and squeeze the elastic taper-lock when the screw was rotated by the motor. At the same time, the elastic taper-lock will take place elastic deformed which brought about radial expansion. Function of centering device will be achieved.

\section{Finite element analysis of centering device}

\subsection{Establish finite element model}

The process of expansion centering was simulated by using the ABAQUS finite element software non-linear analysis technology. Complicated kinematic relationship between taper-lock, expanding mandrel body, drive screw and motor will be simplified. Just consider the movement which taken place among taper-lock and expanding mandrel body. Expanding mandrel body was set as analytical rigid body which doesn't bring about elastic deformation only axial movement. The three-dimensional finite element model was set up shown in figure 3.

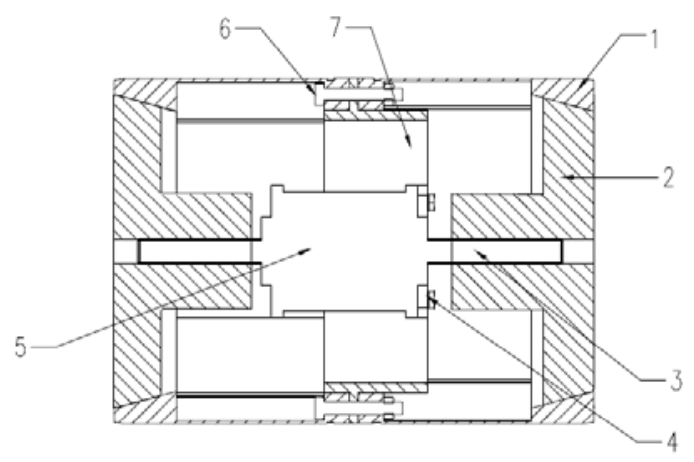

1.Taper-lock 2. Expanding mandrel 3.Fixing screw 4. Fixing bolts

5.Motor 6.Attachment bolts 7. Motor base

Fig.1. Assembly drawing 


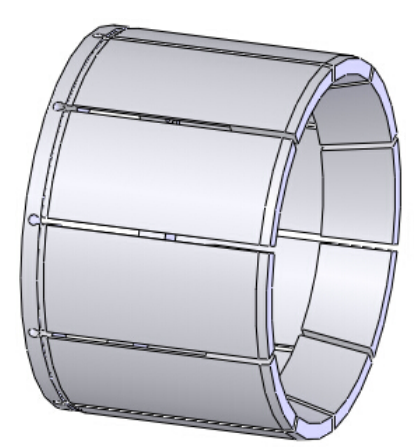

Fig.2. Taper-lock

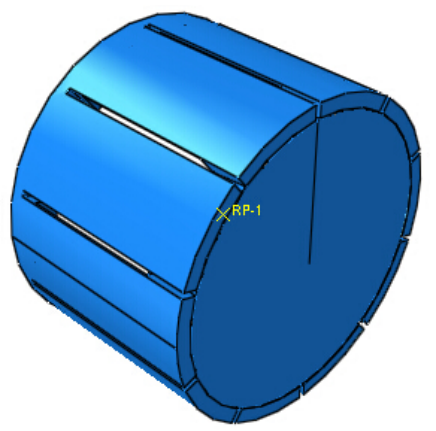

Fig.3. Finite element model

\subsection{Property and meshing}

The 8-node solid element was used in the processing of meshing. The element which each node has three translational degrees of freedom along the $\mathrm{X}, \mathrm{Y}, \mathrm{Z}$ direction has the feature of super-elastic, creep, large deformation and wide strain capacity. Expanding mandrel doesn't need meshed which was analytical rigid body. The meshing of taper-lock is shown in figure 4.

\subsection{Boundary conditions and loads}

A reference point RP-1 which in the analytical rigid body center of mass was established in the finite element analysis. Displacement load was applied in point RP-1. The left side of taper-lock was restricted to limit X, Y, Z directions freedom. As shown in Figure 5. Establish face-face contact element. The contact area between taper-lock and expanding mandrel body was wedge-shaped tapered surface. The wedge surface of expanding mandrel body was active surface. The wedge surface of Taper-lock wedge was driven surface. As shown in Figure 6.

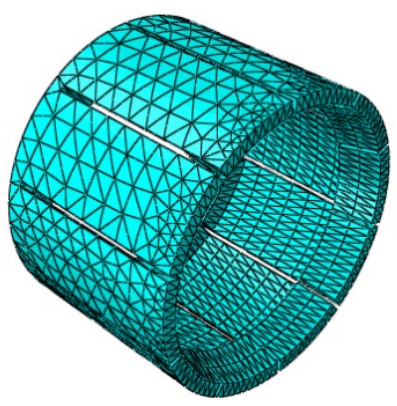

Fig.4. Meshing

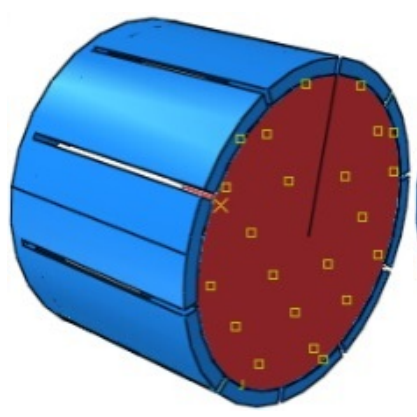

(a)Active surface

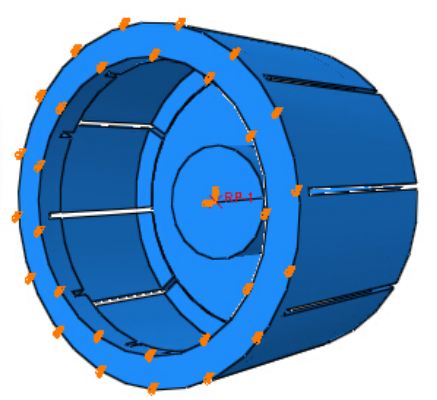

Fig.5. Boundary conditions and loads

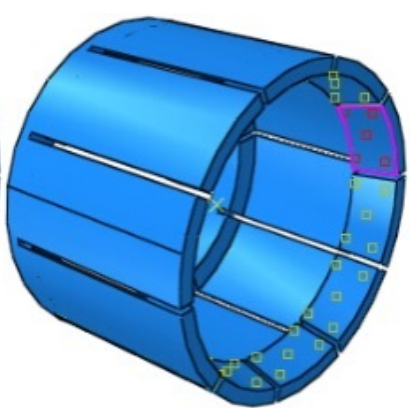

(b) Driven surface

Fig.6. Surface contact

\section{Centering device design and optimization}

\subsection{Centering device design}

Different load displacement was applied in the expanding mandrel reference point. The elastic taper-lock will take place elastic deformed which bring about radial expansion, as shown in Figure 7.The relationship between the amount of displacement and radial expansion shown in figure 8. This phenomenon that value of radial 
expansion will increaser with expanding mandrel body take place axial displacement. It can be seen from the deformation nephogram. The amount of taper-lock radial expansion is 0 millimeter when the expanding mandrel body axial moves 0 millimeter. The amount of taper-lock radial expansion is 4 millimeter when expanding mandrel body moves 10 millimeter. The amount of taper-lock radial expansion is 5.4 millimeter when expanding mandrel body moves 13 millimeter. However the amount of taper-lock radial expansion is 0millimeter when expanding mandrel body moves 15 millimeter. The reasons for this phenomenon is expanding mandrel body thickness value is too small that causes the wedge surface of expanding mandrel body and the wedge surface of taper-lock falling out with each other. Therefore the amount of taper-lock radial expansion is 0 millimeter.

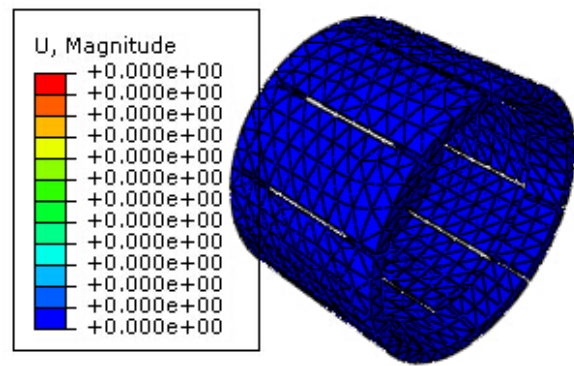

(a) $0 \mathrm{~mm}$

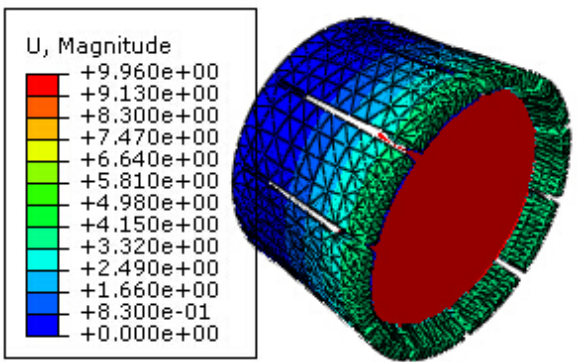

(b) $10 \mathrm{~mm}$

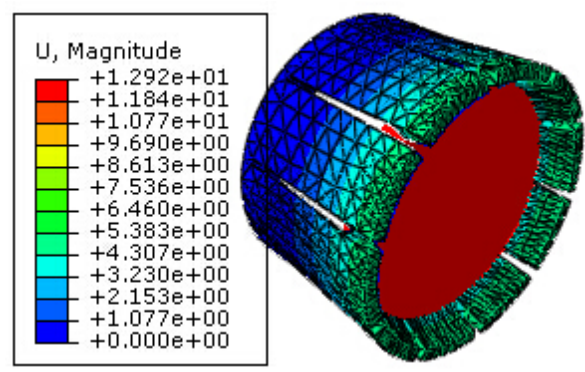

(b) $13 \mathrm{~mm}$

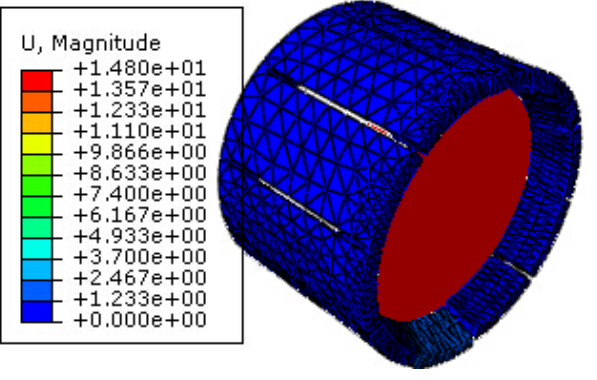

(d) $15 \mathrm{~mm}$

Fig.7. Taper-lock deformation nephogram

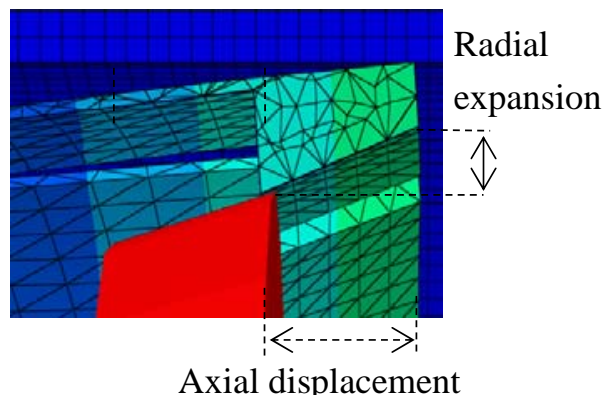

Axial displacement

Fig.8. Relationship between axial displacement with radial expansion

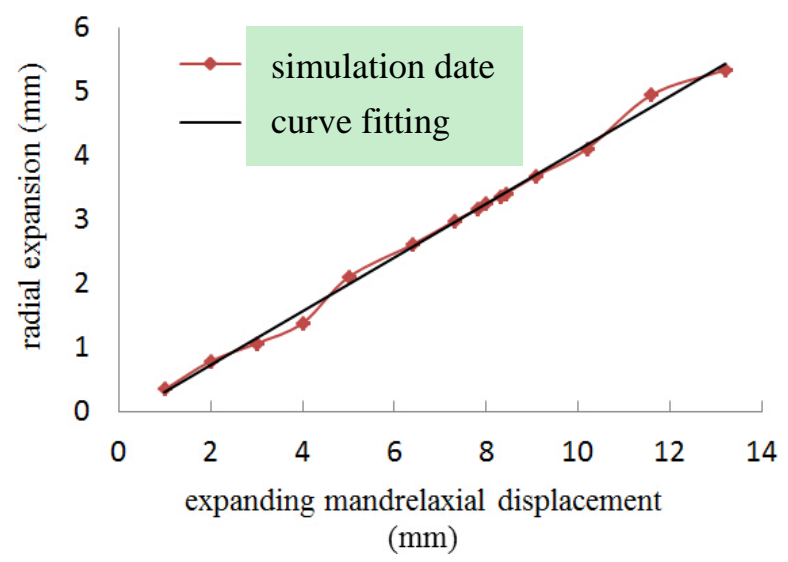

Fig.9.Curve fitting between axial displacement with radial expansion 
The relationships graph between the amount of expanding mandrel body displacement and taper-lock radial expansion is established by the way of data approximating. As shown in figure 9. According to the fitted curve thickness of expanding mandrel body is designed.

In this paper, the adaptive pipe diameter flexible expansion centering device can accommodate gun barrel diameter which ranging from 110 to 130 millimeter. The original diameter of centering device is 110 millimeter. A positive relationship between expanding mandrel body displacement with taper-lock radial expansion can be seen from the graph. The taper-lock will expand 5 millimeter in the radial direction when the expanding mandrel body axial moves 13 millimeter. The maximum diameter which centering device can adapt is 120 millimeter. The taper-lock will expand 10 millimeter in the radial direction when the expanding mandrel body axial moves 25 millimeter. The maximum diameter which centering device can adapt is 130 millimeter. Therefore, in order to achieve the requirement that the adaptive pipe diameter flexible expansion centering device accommodate gun barrel diameter which ranging from 110 to 130millimeter. The thickness of expanding mandrel body is designed 30 millimeter.

\subsection{Structural Optimization}

After different displacement loads is applied in expanding mandrel. Nephogram of taper-lock stress concentration is shown in figure 10. Maximum equivalent stress is 1371GPa under 10 millimeter displacement loads. Maximum equivalent stress is 1742GPa under 13 millimeter displacement loads. Stress concentration can be seen form nephogram that mainly occurs in the gouges notch portion of taper-lock flange structure, as shown in figure 11. Therefore, the gouges notch portion of taper-lock flange structure is treated with rounded corners.

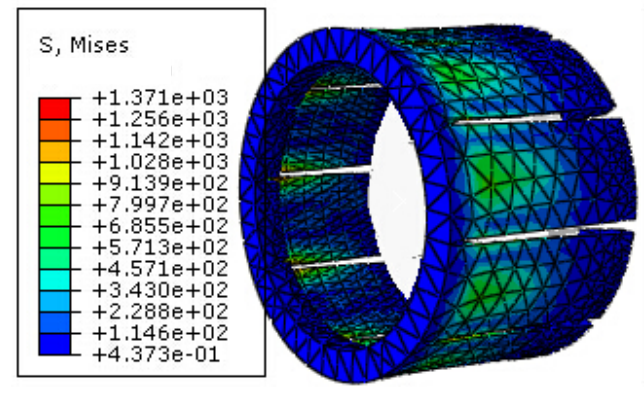

(a)The stress nephogram-10mm

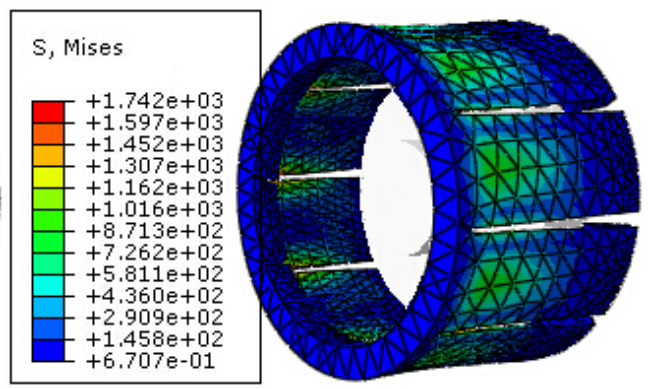

(b)The stress nephogram-13mm

Fig.10. The stress nephogram

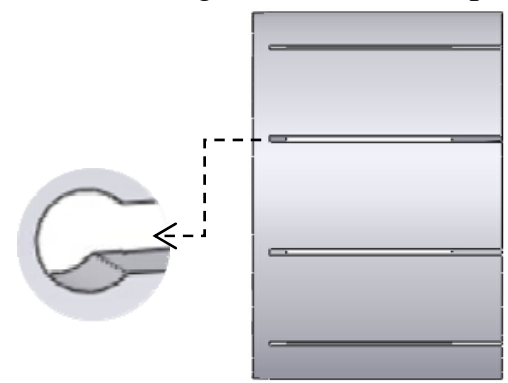

Fig.11. Rounded optimize

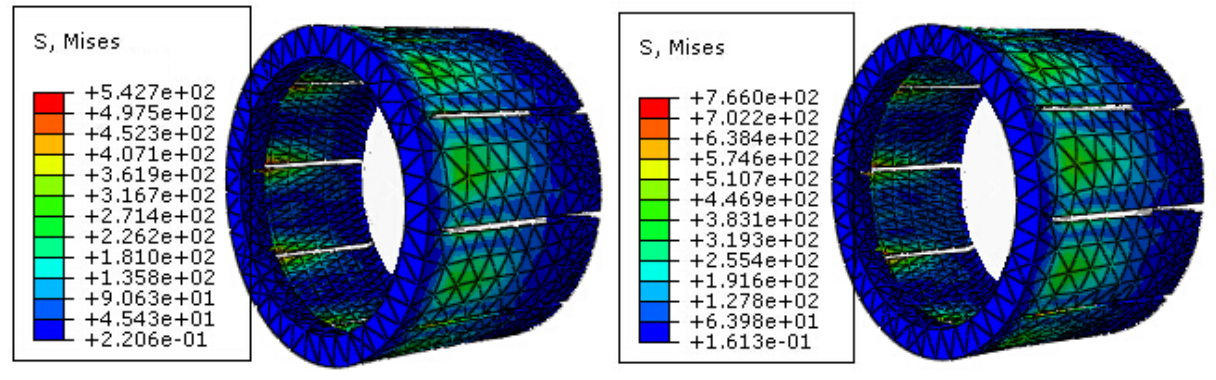

(a)The optimized stress nephogram-10mm ～(b)The optimized stress nephogram-13mm Fig.12. The optimized stress nephogram 
Through optimizing, maximum equivalent stress dropped from 1371GPa to 543GPa under 10 millimeter displacement loads and 1742GPa to 766GPa under 13 millimeter displacement loads. Optimized stress result nephogram shown in figure 12. Stress concentration of taper-lock is reduced effectively and reliability of flexible expansion centering device is improved

\section{Conclusion}

In this paper, a new type of adaptive diameter flexible expansion centering device is designed by applying expansion positioning principle. The process of expansion centering is simulated by using the ABAQUS finite element software non-linear analysis technology.

(1) Relationship between the expanding mandrel body axial displacement and taper-lock radial expansion is positive. Therefore the thickness of expanding mandrel body will directly affect the amount of taper-lock radial expansion. In order to achieve the requirement that the adaptive pipe diameter flexible expansion centering device accommodate gun barrel diameter which ranging from 110 to 130millimeter. The thickness of expanding mandrel body is designed 30 millimeter.

(2) Through optimizing the taper-lock structure and treating the taper-lock flange structure gouges notch portion with rounded corners, the phenomenon of stress concentration of taper-lock is reduced effectively and the reliability of flexible expansion centering device is improved

(3) Compared with the previous centering device, the centering contact area is transposed from point contact to surface which enlarged the contact area of centering and improved the reliability of flexible expansion centering device.

\section{Acknowledgement}

In this paper, the research was sponsored by the project of Technology Foundation of National Defense which belongs to The Commission of Science, Technology and Industry for National Defense of the PRC (Project No. GKY201201).

\section{References}

[1]Weck M, Schmidt M. A new method for deter mining geometric accuracy in the axis of movement of machine tools [J]. Precision Engineering, 1986, 8(2): 97-103.

[2] Cheng S, Huang P. Barrel straightness detection method and measuring element selection [J]. Technology Foundation of National Defence, 2007, 02:53-55.

[3] Journet B, Bazin G, Bras F. Conception of an adaptive laser range finder based on phase shift measurement[C]. Proceedings of IEEE IECON, 1996, 2: 784-789.

[4] Bai B X, Ma H. System for artillery body inside chamber straightness [J]. Journal of Changchun University of Science and Technology, 2002, 25(2): 37-39.

[5] Ye T F. Gun Barrel detection technology and system design [D]. Zhejiang: Zhejiang University, 2005.

[6] Zhang C G. Gun Barrel bore-parameter detection technique [D]. Jilin: Jilin University, 2009.

[7]Song X. Detection of Gun Barrel centerline straightness [D].Changchun: Changchun University of Technology, 2013.

[8] Ji L J. Research on the measuring instrument of gun barrel axis straightness [D]. Sichuan: Sichuan University, 2003.

[9] Meng X H. Theoretical research on model \& methods of deep-hole straightness detection [D]. Shanxi: North University of China, 2014. 